ARTIGOS
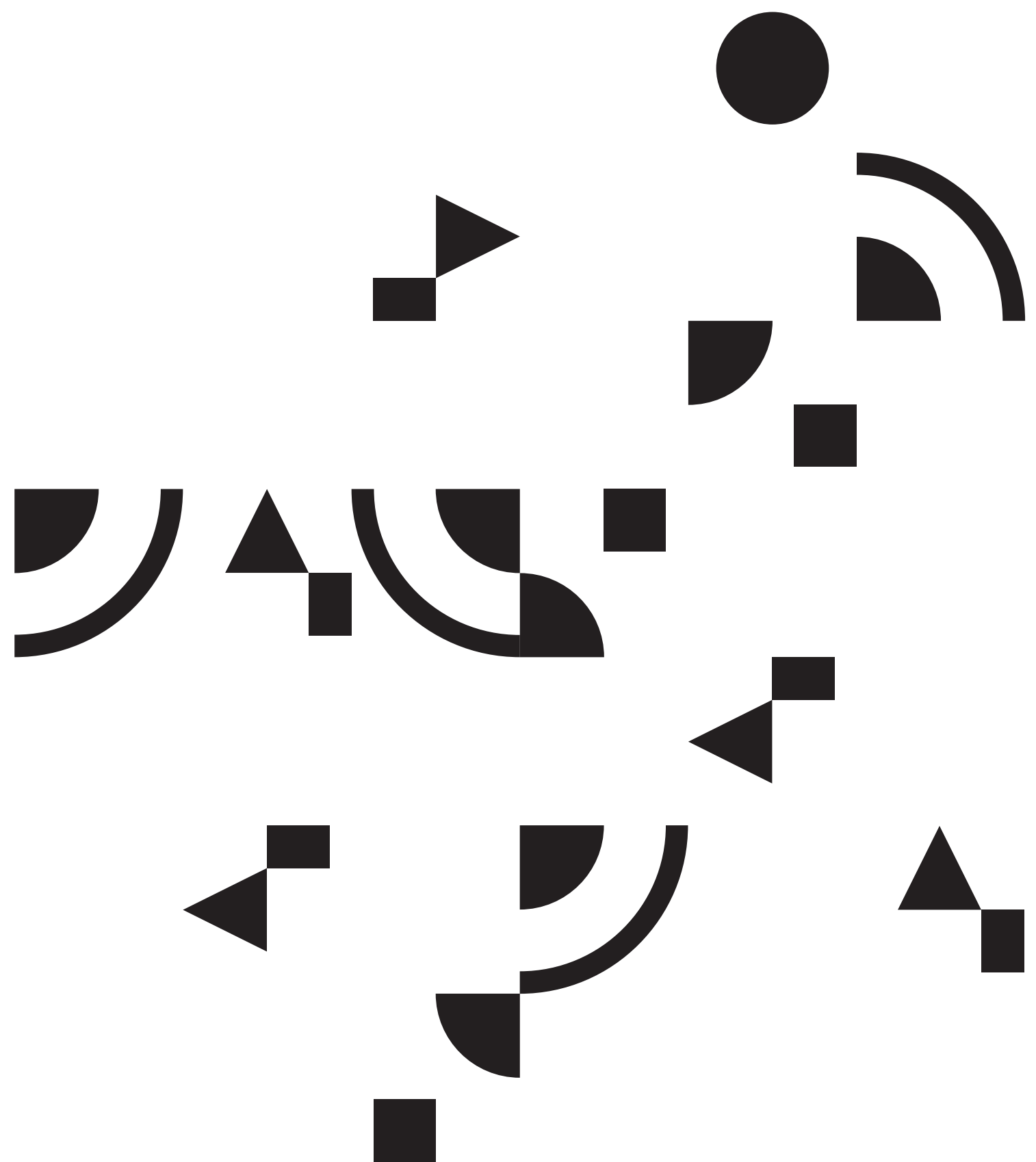


\title{
Relações de idade e geração na Educação Infantil: ou porque é bem mais melhor a gente ser grande
}

\author{
Patrícia Dias Prado*
}

\section{Resumo}

Ao investigar as relações de idade e geração entre crianças pequenas e delas com as professoras em contexto educativo e coletivo na esfera pública, este artigo busca traçar um percurso reflexivo de rupturas teóricas, no campo da Antropologia e da Sociologia, aliadas às produções brasileiras, italianas e portuguesas na área da educação da infância, na tentativa de compreender os grupos de idade a partir de uma perspec-

* Professora Doutora do Departamento de Metodologia de Ensino e Educação Comparada, Faculdade de Educação, Universidade de São Paulo (USP/SP), Brasil. patprado@usp.br tiva geracional. Confronta os saberes infantis e suas culturas inscritas na troca e na negociação, com a lógica dominante sem negociações que afirma que elas não podem e não conseguem. Dois pontos balizam este estudo: a herança social, sua natureza e garantia de reprodução do mundo da ordem numa sociedade capitalista excludente; e a transgressão das crianças pequenas, suas possibilidades de não somente reproduzir, como também de questionar as determinações cronológicas, etapistas e geracionais impostas.

\section{Palavras-chave}

educação infantil; idade; geração; culturas infantis. 


\title{
Age and generation relationships in Early Childhood Education: or "because it is much better for us to be big"
}

\begin{abstract}
By investigating the relationship between age and generation among small children and between them and their teachers in an educational and collective context in the public sphere, this article aims to draw a reflective journey of theoretical rupture in the field of Anthropology and Sociology, allied with the Brazilian, Italian and Portuguese productions in the area of education in early childhood, in an attempt to understand the age groups from a generational perspective, thus comparing the children's knowledge, their childhood cultures present in the exchange and negotiation, with the dominant logics, with no negotiations, that states that they cannot do and cannot manage to do. Two points guide this study: the social inheritance, its nature and guarantee of reproduction of the world of order within an excluding capitalist society, and the transgression of small children, their ability to not only reproduce, but also to challenge the chronological, stage and generational determinations imposed.
\end{abstract}

Key words early childhood education; age; generation; childhood cultures. 
As temáticas deste trabalho partem de uma pesquisa de doutorado concluída e se referem às relações de idade e de geração entre crianças pequenas brasileiras (de 3 a 6 anos) e delas com as professoras, em espaços coletivos e educativos na esfera pública, denominados creches e pré-escolas ${ }^{1}$.

Por meio de uma pesquisa qualitativa de base etnográfica, atenta para o fazer e o dizer de palavras e gestos, para a elaboração e a reelaboração social dos sistemas classificatórios (neste caso, das idades), - tarefa da Antropologia no campo educativo, segundo Lovisolo (1984) -, foi realizada uma observação participante (Foot-Whyte, 1990; Geertz, 2001), com roteiro prévio, no cotidiano de uma instituição de Educação Infantil paulista, em um bairro de padrão popular e médio que integrava uma creche e uma pré-escola. Durante um ano letivo, foram observadas as atividades comuns e incomuns de duas turmas de crianças (maternal de 3 e 4 anos e pré de 5 e 6 anos), em sua maioria, filhas e filhos de trabalhadoras e trabalhadores (Prado,2006).

Observei, diariamente, momentos em que as crianças estavam em suas respectivas turmas ou todas juntas compartilhando o parque ou outros espaços. Atenta para suas brincadeiras, linguagens, expressões, conversas, relações, nos diversos espaços e tempos da jornada educativa (salas, galpões, parques, alimentação, higiene, passeios, reuniões), fiz registros posteriores, por meio de um caderno de campo; de fotografias, realizadas pelas próprias crianças e com elas discutidas em conversas informais; de entrevistas semiestruturadas com as professoras; de análise de documentos oficiais e do projeto político-pedagógico da instituição.

A partir da Antropologia e da Sociologia, articuladas às produções brasileiras, italianas e portuguesas, no campo da educação da infância, foi possível ultrapassar um modelo etnográfico somente descritivo, evidenciando as “vozes" das crianças pequenas, concebendo as relações como imersas na alteridade, compreendendo a noção de cultura e sua dinâmica naquilo que se observa e como se observa, envolvendo necessariamente o contexto histórico, a percepção da natureza e das condições dos sujeitos, as relações sociais que se estabeleciam e a subjetividade da pesquisadora.

Apresentando as crianças não somente como reprodutoras das determinações cronológicas e geracionais impostas, mas também como inventoras de novas formas de se ter determinada idade, em espaços privilegiados de relações diversas (não somente de idade e de geração, como também de classe social, de etnia, de gênero, etc), busco discutir sobre es-

1. Este artigo é uma versão revisada e ampliada de comunicação apresentada no Simpósio Internacional Encuentros Etnográficos con Niñ@s y Adolescentes en Contextos Educativos. IDES, Buenos Aires/Argentina, out. 2009. 
tes grupos de idades, ou grupos etários, a partir de uma perspectiva geracional e das relações inter e intrageracionais, e sobre suas implicações para a construção de uma Pedagogia da Educação Infantil que conheça quem são as crianças.

Portanto, por meio de pesquisa com as crianças, apresento um percurso reflexivo de rupturas teóricas, que ultrapassam as concepções de hereditariedade cultural, no sentido de compreender as atuais formas de produção cultural e a participação ativa das crianças nesse processo (Callari Galli, 2005).

Muitos são os estudos antropológicos (Fortes, 1984; Malinowski, 1983; Radcliffe-Brown, 1990) que abordam, particularmente, a questão da ordem, da herança e da geração, concentrando seu locus de análise nas relações sociais, nas sociedades específicas, especialmente, nos grupos familiares e de parentesco.

Tanto nessas sociedades diferenciadas, como em qualquer outra em que a perpetuação da linhagem e de sua herança se dá entre pais e filhos, evidenciam-se formas particulares na ordem das sucessões. Em nossa sociedade, essa disposição inscreve-se na continuidade do pai (que encarna a linhagem) e o essencial de sua herança paterna:

[...] isto é, uma espécie de "tendência a perseverar no ser", a perpetuar a posição social que nele reside, muitas vezes é preciso distinguir-se dele, superá-lo e, num sentido, negá-lo; empreendimento que não ocorre sem problemas, seja para o pai, que quer e não quer esta superação assassina, seja para o filho (ou a filha), que se acha diante de uma missão dilaceradora e passível de ser vivida como uma espécie de transgressão (Bourdieu, 1997, p.7-8).

Segundo o mesmo autor, para todas as categorias sociais, em graus diferenciados, a ordem de transmissão da herança também depende dos vereditos das instituições de educação, que funcionam como um princípio de realidade poderoso, responsável por muitos fracassos.

Uma vez competindo com a autoridade e a vontade do grupo familiar, a instituição educativa poderá confirmar ou contrariar os julgamentos e as sanções colocadas pela família, influenciando de forma decisiva na educação das crianças. Nas contradições das sucessões, muitas vezes genéricas, entre as disposições do herdeiro e o destino encerrado em sua herança, herdar é substituir essas disposições para perpetuar um determinado projeto, aceitando ser instrumento dessa reprodução e um "herdeiro sem história” (Bourdieu, 1997, p. 9). 
As conquistas deste herdeiro (que aqui considero as crianças) são, por procuração, a realização das conquistas da própria família e/ou da instituição educativa. Para uma boa transmissão da herança, a primeira está subordinada à segunda, como, por exemplo, nos contextos educativos de creches e pré-escolas, em que o sucesso ou o fracasso escolar estariam relacionados às atitudes e às condutas das crianças pequenas, no sentido de sua integração ou não a esses espaços.

De que herança queremos que as crianças sejam herdeiras? Aquelas que aceitam e se apropriam da nossa herança escapam das antinomias. As transgressoras são vistas como fracassadas em seu êxito, como se as posições cobradas, o projeto ideal e esperado não pudessem ser ultrapassados, rompidos. A família e a instituição educativa não pressupõem, então, o novo?

As crianças estão desamparadas tendo que decidir sozinhas suas certezas, suas possibilidades e fazem isso pelo inverso, pois sabem, desde muito cedo, não poderem, não conseguirem, não serem capazes, não entenderem. Isso seria imaturidade advinda da pouca idade? Elas conhecem, pela comparação entre aquilo que thes é dito e aquilo que observam (e a partir do que concluem), as contradições dos adultos e da sociedade.

É a respeito dessa herança que quero discutir, confrontando os saberes das crianças, suas culturas infantis inscritas na troca, na negociação e no compartilhar e fazer as coisas juntas, com a lógica de uma sociedade dominante, sem negociações, que afirma que elas não podem, não conseguem e não entendem. Ou seja, dois pontos balizam essa busca: a herança social, sua natureza e garantia de reprodução do mundo da ordem, numa sociedade excludente como a nossa; e a transgressão, a possibilidade de questionar o que existe e de instaurar uma nova ordem, por meio da cultura e das relações com a sociedade apreendida por suas contradições e vazios, que permitem o novo, o inusitado, a descoberta.

Uma ordem social, como a nossa, instaura o desejo da sucessão, da herança, do mais velho para o mais novo, do adulto para a criança, do mais experiente para o menos experiente, sempre em termos da idade. Tão bem sinalizada está essa ordem de sucessão, que canaliza, reforça ou contraria as múltiplas formas de estabelecimento de relações sociais presentes nos espaços educativos.

$\mathrm{Na}$ incompletude confirmada dos herdeiros, um princípio primeiro de seu projeto ideal corresponde ao tornar-se adulto, "gente grande”, maduro, experiente, mais veIho, e o mais rápido possível. As crianças demonstram, a partir disso, uma necessida- 
de emergente de crescer, de ser mais velhas, de se tornar adultas, tal como mostra o diálogo a seguir, em uma das conversas informais com elas no parque:

Eu queria ser grande - disse-me, certa vez, uma menina do pré.

Por quê?- eu perguntei.

Porque sim - respondeu-me.

Porque é beeeem mais melhor a gente ser grande! - ela completou.

Para quê? - perguntei novamente.

Pra dirigir, pra sair assim... - respondeu-me.

Pra mandar em todas as crianças! - disse outra menina maior, que acompanhava a conversa.

Pra fazer as crianças fazer tudo que eu quiser - completou outro colega.

E para que mais? - perguntei, interessada, ao grupo de crianças que comigo conversava.

Pra viajar, namorar, ter filhos, cuidar deles - disseram as crianças

Pra ter dinheiro, pra comprar brinquedo, roupa... - completaram.

Quero me ater aqui à lógica sensivelmente apontada nas vozes das crianças em relação ao conceito que fazem de seu projeto ideal em curso e de seus sucessores. Elas demonstram já saber que o mundo construído pelos adultos as privilegia, com possibilidades infinitas e não restritas como as que elas são submetidas, seja para dirigir, namorar, viajar..., seja para ter filhos, dinheiro, brinquedos. E, no sentido da ordem instituída, querem crescer para mandar em todas as crianças.

Algum adulto as contestaria?

Desnaturalizando o dado e projetando, no estranhamento, as familiaridades (Da Matta, 1978), busco supor quais as causas, as razões e as funções deste costume tido, segundo Lovisolo (1984, p.58), como "naturalmente natural” por nossa própria sociedade. E o que significa isso para as crianças? Uma das normas, regras da ordem familiar e educacional? Por que o campo educativo também funda um mundo instaurando essa mesma ordem? Como seria um mundo, que a subvertendo, fosse comandado pelas crianças?

As crianças pequenas observadas evidenciavam sua generosidade nas relações sociais que estabeleciam com as professoras, comigo e com outras crianças, principalmente, quando estavam entre turmas diferentes. Atendiam às so- 
licitações das professoras (das duas turmas), envolviam-se nas suas propostas, convidavam-me para as brincadeiras, abraçando, carregando e zelando pelas crianças menores (no caso das maiores). Mostravam-se orgulhosas de compartiIhar brincadeiras com as crianças maiores (no caso das menores), em detrimento das animosidades, também explícitas, principalmente entre as crianças da mesma idade e a turma, mas que não se constituíam como formas predominantes no estabelecimento de suas relações.

Mais do que isso, as crianças maiores do pré revelavam observar as contradições dos adultos, quando o desejo de "ser gente grande" surgiu em outra conversa informal na varanda externa da sala:

Eu quero ser gente grande, mas legal - disse uma das meninas.

Que conversa ... - completou outra menina.

Que deixa brincar..., que brinca um pouco, até - complementou um menino.

Também na produção da Scuola Comunale dell'Infanzia Diana Reggio Emilia (Caiumi et al, 1999), as crianças pequenininhas italianas, de 3 anos, autodenominadas de grandes, distinguem-se, entre tantas coisas, dos adultos, que são, contraditoriamente, aqueles que gostam de férias, mas não as têm, pois trabalham e trabalham; gostam de ser ouvidas, mas falam juntas ao mesmo tempo; e não têm medo de nada (só de fantasma e de acidentes), mas quando têm, pedem para acender as luzes.

Pesquisando crianças grandes, portuguesas, de 7 a 9 anos de escolas primárias das aldeias de Óbidos, Saramago (1994) diz que as questões de autoridade e de poder construídas pelas crianças em relação aos adultos são expressas como fatores externos ao grupo infantil, que se autodenomina como objeto de poder, cabendo aos adultos o papel da autoridade. Assim como as crianças maiores portuguesas, as crianças pequenas pesquisadas revelavam a percepção de ser objetos de poder e, portanto, expostas às mais diversas formas de utilização abusiva e arbitrária dessa mesma autoridade.

Com o objetivo de disseminar práticas familiares de educação das crianças soviéticas, em uma sociedade socialista em construção, Makarenko (1981) critica a autoridade baseada em princípios arbitrários com tendência a construir uma obediência a qualquer preço. 0 autor atribui à autoridade do conhecimento, consequentemente, à autoridade da colaboração, formas capazes de orientar cuidadosamente as crian- 
ças, por meio da solidariedade e da observação atenta dos adultos, os quais devem evidenciar suas preocupações e sua segurança em propor que elas contornem suas dificuldades, superem os obstáculos e resolvam os problemas mais complicados.

No momento em que as crianças pesquisadas se imaginavam adultas, reproduzindo os papéis de autoridade que vivenciavam, para mandar em todas as crianças, elas revelavam uma esfera de poder. Legitimam e reproduzem, até certo ponto, padrões sociais que orientam certas formas de estabelecimento de suas relações com os adultos e vice-versa.

Digo até certo ponto, pois as crianças pequenas pesquisadas, colocando-se como observadoras constantes, revelavam que compreendiam uma outra ordem possível deflagrada no convívio entre crianças de idades diferentes e desencadeadora de suas capacidades de tirar suas próprias conclusões a partir daquilo que observavam e/ou experimentavam:

Olha, eu sou mais grande..., maior que ele e não consigo fazer! Disse um dos meninos da turma do pré, enquanto tentava, assim como outro menino da turma do maternal, dependurar-se de ponta-cabeça no trepa-trepa em um dos momentos compartilhados de parque. 0 menino menor, ouvindo o comentário do colega maior, exibiu com orgulho suas habilidades no brinquedo, enquanto o colega maior esforçava-se em observar e em reproduzir o que ele fazia.

Vários foram os momentos registrados no diário de campo em que, nesse mesmo sentido, a ordem instituída era subvertida pelas crianças, revelando, assim, que não são somente as mais velhas ou maiores em idade (tidas na literatura como as mais experientes) que são imitadas pelas mais novas ou menores. 0 sentido inverso desta proposição nega uma evolução linear de nossas habilidades e capacidades na ordem cronológica, então instituída, e apesar dela. As habilidades e capacidades intercruzam-se, complementam-se, compõem-se, contrariam-se na mistura.

As crianças evidenciavam, ainda, que maiores e menores vivem experiências diversas e semelhantes quando estão no espaço educativo (e fora dele), e que também aprendem umas com as outras, independentemente de suas idades.

Uma noção de desenvolvimento da infância - diferentemente do desenvolvimento psicológico individual da criança - pressupõe o reconhecimento de seu crescimento histórico, social, político e cultural para a elaboração de uma arquitetura da infância, como diz Qvortrup (2000, p.107): 
Não é preciso muita imaginação para perceber, que este sentido de infância - o entendimento de uma arquitetura da infância ou o espaço de vida na qual todas as crianças orientam suas vidas - tem mudado completamente sua forma e sua satisfação no tempo.

Adotando e enfatizando alguns possíveis contornos desta arquitetura da infância, ou das infâncias (Qvortrup, 2010), novas tendências, teorias, metodologias devem ser reivindicadas para que as crianças sejam estudadas, sob seus próprios pontos de vista, como já destacam as produções recentes das pesquisas no campo da educação da infância no Brasil. (Faria; Dermatini; Prado, 2009; Martins Filho; Prado, 2011). Para tanto, o mesmo autor (Qvortrup, 200o) anuncia a ideia dessa possível inversão da ordem instituída, quando afirma que as crianças podem ser dependentes dos adultos, mas que os adultos também são dependentes delas, abrindo caminho para compreender as relações e proposições entre a infância e outras gerações e ampliando o entendimento das relações e dos conceitos na própria infância.

Entendendo a infância como um conceito relacional, plural (que difere de acordo com sua circunstância específica de vida), apresentado dentro de ordens geracionais, o mesmo autor ainda propõe a discussão sobre a categoria geracional da infância na relação com outras como a juventude, a idade adulta e a velhice.

Um exemplo importante desta relação pode ser evidenciado nos estudos de Aguiar (1998, p.159) com o povo da Barra da Aroeira, no estado de Goiás.Todos apontavam a importância das brincadeiras para a vida e os seus benefícios, ao reunir as pessoas, para o divertimento, para os contatos afetivos, para a alegria, “... em que adultos e crianças participam igualmente, sem privilégios devido às diferenças de idade”. Isso revela uma concepção de infância na qual as crianças são tão capazes quanto os adultos, e não inferiores a eles. Por isso, eles brincavam juntos e, por vezes, eram elas quem iniciavam as brincadeiras.

Algo semelhante foi descrito por Baldus (1972), em seus estudos sobre o ciclo de vida dos índios Tapirapé. Ele enfatiza o respeito e a compreensão com que os adultos tratavam as crianças, levando suas ideias em consideração e não estabelecendo uma relação de superioridade em relação a elas. 0 mesmo pode ser observado em muitas das tribos indígenas do Brasil (conforme Silva; Macedo; Nunes, 2002), onde não há castigos, humilhações ou punições às crianças.

Entre os Xikrin, um dos grupos Kaiapós do Pará, Cohn (2005) observa que os pais, 
avós e irmãos podem perder a paciência com a criança e lhe bater, arranhar ou morder, mas desprezam o modelo das famílias brancas que gritam ou batem muito em seus filhos. Como eles acreditam que, se as crianças chorarem muito, elas perdem seu Karon (“alma”), tomam todo cuidado com elas, tratando-as bem, distraindo-as, consolando-as para isso não aconteça.

Kluckhohn (1963) diz que o castigo corporal é raro entre muitas das sociedades indígenas, não por uma generosidade inata de seus povos, mas porque isso não corresponde, nem se solidariza com o desenvolvimento individual e social considerado como ideal.

Recentemente, investigando as crianças índias brasileiras Guarani/Kaiowá e as da Aldeia Pirakuá/MS, Noal (2006) reafirma o estabelecimento de relações solidárias, de brincadeiras, de sociabilidades, entre os adultos e as crianças e entre elas, maiores e menores, observando a construção de uma educação que se consolida nas desidades, ou seja, na ruptura de critérios segregadores em relação à idade.

Não é inato na sociedade, o entendimento da trajetória do curso da vida e de sua periodização, assim como o estabelecimento de relações entre crianças e adultos num cenário escarpado e obscuro, “onde sopram ventos e tensões, um nó complicado e crucial de toda a nossa cultura" (Montes, 1991, p. 12). Também não é inato associarmos os momentos ou fases da vida, infância, juventude, vida adulta ou velhice, a uma ideia de crise, em que:

Cada fase de transição tende a ser interpretada pelo indivíduo como uma crise de identidade e o curso da vida é construído em termos de necessidade antecipada de confrontar e resolver essas fases de crise (Debert, 1993, p. 20).

Com a institucionalização do curso da vida na sociedade moderna baseada numa concepção punitiva, individualista, particular e singular de homem, é que as noções de crise de idade e de conflitos entre gerações passam a ter sentido, já que as passagens de um momento para outro e suas inter-relações geracionais são percebidas como dramas individuais, como experiências únicas, embora esperadas por todos ao atingir determinada etapa da vida.

Embora todos saibam o que vai se passar, porque há um script social para isso, as pessoas vivem as diferentes fases da vida como experiências abso- 
lutamente singulares. Para estas experiências, a cultura individualista da sociedade contemporânea constrói uma rede de significados que dá aos indivíduos, ao mesmo tempo, modelos de ação e condições de interpretação da realidade. As crises e os conflitos são internalizados como fatos individuais de ordem privada. Ninguém pensa neste instante que está vivendo algo que é dado culturalmente (Barros, 2003, p. 3).

Assim como Barros (2003) e Moragas (2003) - a primeira, por meio de uma análise antropológica das relações entre avós, filhos e netos cariocas; e o segundo, de uma análise sociológica das relações entre as gerações, a partir do enfoque da Gerontologia Social -, além de outros interessados em investigar as relações intergeracionais nas sociedades contemporâneas, busco ampliar, para além de seus significados referentes ao tempo histórico, o conceito de geração que agrupa pessoas de acordo de suas idades, e não somente como conjunto de pessoas nascidas na mesma época, ou como função pela qual se reproduzem os seres organizados.

No campo científico, Britto da Motta (2004, p. 350) apresenta sinteticamente três sentidos principais para o termo "geração" que se cruzam como: os "coortes" ligados às referências estatísticas e demográficas, que designam um conjunto de pessoas nascidas no mesmo intervalo de tempo, exposto a eventos de caráter demográfico; os "grupos etários", de tradição antropológica, que expressam o conceito em termos de categorias ou classes de idade, mas também tangenciam aspectos não cronológicos, enfatizando os atributos culturalmente definidos, os sentidos classificatórios das posições na família e na organização social mais ampla; e a "geração", propriamente dita, num sentido eminentemente sociológico, que se refere ao conjunto de pessoas que vivem em determinada época, têm aproximadamente a mesma idade e compartiIham alguma vivência ou experiência.

Concebo a categoria geracional, vinculando os sentidos de grupos etários e de geração, como as vivências de acontecimentos semelhantes que definem trajetórias presentes, passadas e futuras, que originam atitudes, sentimentos, modos de ser e de viver, que permitem identificar seus membros como sujeitos de uma mesma geração fenômeno social que representa "um tipo particular de identidade de situação de 'grupos de idade' mergulhados num processo histórico social” (Mannheim, 1928, p. 137).

Mesmo dedicando-se aos estudos sobre a juventude e os grupos jovens para discutir geração - assim como o foco das produções brasileiras até os anos 1970) -, 
Mannheim (1928, p. 124) traz uma importante inspiração analítica para a pesquisa, quando propõe a categoria "unidades de geração" para a possibilidade ou não de formação de grupos concretos na contemporaneidade, pois cada momento histórico se realiza com a simultaneidade de gerações que não têm as mesmas experiências e trajetórias de vida: "Todas as pessoas convivem com pessoas da mesma idade e de idades diferentes [...] Mas para cada uma 'o mesmo tempo' é um tempo diferente...”.

Para Moragas (2003), o estudo das gerações, iniciado por Mannheim (1928), por meio da análise de seus grupos etários com experiências compartilhadas, é atualmente considerado uma forma útil de examinar a complexidade das sociedades contemporâneas. Entretanto, as relações entre gerações, como tantos fenômenos sociais, não se apresentam somente na forma de crise, mas elas também podem ter um resultado positivo inscrito na cooperação. A característica cooperativa e solidária é amplamente discutida e apontada nos diversos estudos, que têm priorizado o convívio entre crianças e velhos, numa reflexão das relações entre infância e velhice (Bosi, 1983; Gusmão, 2003; Park,1999; Sgritta, 2002,).

Também se dedicando a estudar as culturas dos jovens portugueses, Pais (1993) aponta para duas correntes teóricas da sociologia da juventude, que aqui, no caso das culturas infantis, encontram férteis relações analíticas possíveis de serem problematizadas. Assim como Fernandes (1979, pioneiro de uma sociologia da infância brasileira, que enfatiza, por meio do estudo dos folguedos entre grupos infantis, a existência de culturas infantis inscritas na escolha e na obediência às regras e ao espírito de solidariedade e de disciplina adquirida nos grupos com outras crianças de idades diferentes, busquei reconhecer as crianças pequenas pesquisadas como sujeitos que fazem história e constroem culturas em condições dadas.

As relações travadas pelas crianças de diferentes idades nas brincadeiras revelavam, além de sistemas de aquisição de elementos culturais, "atualizações da cultura infantil" (Fernandes, 1979, p.386), comportamentos, formas, expressões, sentimentos, estéticas e expectativas não só verbais, mas por meio de representações, de imagens e impressões, que emergem do conjunto da dinâmica social.

A corrente geracional compreende a juventude como geração social, como uma fase de vida e enfatiza o valor unitário da juventude, tendo como questão central a continuidade e a descontinuidade dos valores intergeracionais. A existência de uma cultura juvenil, de certa maneira, opõe-se à de outras gerações e este anverso assume diferentes formas de descontinuidades intergeracionais, de rupturas e de con- 
frontos. A renovação e a continuidade da sociedade dependem, assim, das relações entre as gerações, dialeticamente submetidas a uma ou outra forma de tensão.

Assim podiam ser compreendidas as culturas infantis observadas neste estudo, entretanto, elas não se opunham, necessariamente, às culturas de outras gerações, mas eram também complementares e interdependentes entre si.

Do ponto de vista das relações entre jovens e adultos, a corrente geracional aponta para os relacionamentos aproblemáticos e problemáticos, ou seja, os sinais de continuidade e de descontinuidade podem se manifestar na interiorização e reprodução de crenças, valores e normas sociais por parte dos jovens, ou por sua ruptura (Pais, 1993). Como historicamente construída, num processo contraditório que the atribui estatuto social e elabora as bases ideológicas e normativas de seu lugar na sociedade, a geração da infância é dinâmica e continuamente atualizada nas experiências e nas práticas sociais.

Nas relações entre as crianças menores e maiores pesquisadas e entre elas e suas professoras, observei uma pluralidade de modos de se ter determinada idade, dinamicamente construída por meio das continuidades e descontinuidades de como se encontravam grandes e pequenos, não somente reproduzindo as normas e regras impostas e o que era esperado para determinada idade, como também, transgredindo-as, inovando a partir delas e propondo novas formas de educação entre idades e gerações semelhantes e distintas.

Enquanto a reprodução social se restringe à análise das relações intergeracionais, ou seja, à análise da conservação ou não das formas das relações sociais entre gerações, na corrente geracional abordada anteriormente, uma outra corrente - a classista - fundamenta o entendimento da reprodução social em termos de reprodução das classes sociais. A transição dos jovens para a vida adulta encontra-se sempre pautada por desigualdades sociais, no que diz respeito à divisão sexual do trabalho e, principalmente, à condição social.

Para a corrente classista, as culturas juvenis são sempre as de classe, produto das relações antagônicas dela, “culturas de resistência” (Pais, 1993, p. 48) e por isso, possuem um significado político. Assim podem ser consideradas as culturas infantis, diretamente associadas ao conceito de classe dominante. Definem-se por relativa oposição às culturas exercidas pelas gerações mais velhas (que fazem parte do padrão dominante), como uma forma de resistência a elas, quando não há sua reprodução.

Trago as culturas juvenis como inspiração para confrontar e refletir sobre as culturas infantis, na pretensão de construir um discurso ambivalente. Assim como as cultu- 
ras juvenis, as infantis podem ser consideradas como culturas de geração, de classe, como ambas, ou como culturas de gênero, de idade, de tamanho, etc., dependendo do ponto de vista analítico que se considere.

Entretanto, ampliando o conceito de cultura nas duas correntes, para além de processos de internalização de normas e de socialização, no sentido antropológico, as culturas infantis (assim como as juvenis) expressam modos de vida específicos, práticas cotidianas de significados e valores compartilhados e construídos, de sociabilidades, de reprodução e também de inovação e invenção.

A construção histórica dessas culturas infantis, marcada pelo distanciamento das crianças do mundo dos adultos e por sua institucionalização, configura na sociedade contemporânea os primeiros espaços educativos pensados exclusivamente para este grupo geracional específico (de o a 6 anos). A separação da geração da infância de outras gerações não se deu, porém, pela institucionalização das crianças, mas pelo fornecimento de elementos fundamentais para a construção de concepções sobre a infância, em condições históricas, econômicas, sociais e políticas diversas. Por isso:

É necessário interrogar-se sobre como as crianças vivenciam os espaços dinâmicos do contexto educativo e que são determinados pela sucessão dos episódios, pela sua recorrência no decorrer do dia, pelo ritmo geral, pelas modulações das várias dimensões; aspectos dinâmicos do contexto educativo que, em um jogo de oscilações entre continuidade e descontinuidade, se traduzem em uma vivência que se articula entre o pólo familiar, do habitual e do previsível, e o pólo do inédito, do inesperado, do estimulante (Nigito, 2004, p. 44).

Partindo desta perspectiva, as mudanças nas políticas públicas e as novas propostas político-pedagógicas, como a dos Agrupamentos Multietários na Educação Infantil2 ${ }^{2}$ transformam tanto o cotidiano das crianças (e também das professoras) quanto as concepções que delas se têm. Com a discussão sobre geração é possível perceber não só o que aproxima

2. Proposta político-pedagógica implementada na rede municipal de Educação Infantil do município pesquisado, que organiza as crianças em três agrupamentos por idade: de 0 a 1 ano e meio, de 1 ano e meio a 3 anos e de 3 a 6 anos, diferentemente das formas tradicionais que ordenam as crianças em grupos de mesma idade. crianças e professoras, nos espaços educativos, como também as culturas que as crianças, entre elas e com as professoras, produzem e elaboram historicamente. 
No caso deste estudo, mesmo evidenciando um processo de socialização e disciplinarização das crianças, observei que as professoras, como grupo de idade ou geração dominante, por isso considerado o mais importante, repartiam interesses comuns com as crianças, quando compartilhavam também seu estatuto social de professoras que as ensinam, não se apresentando como únicos modelos possíveis, demonstrando a capacidade de observá-las e de aprender com elas.

As gerações distintas, que conviviam no espaço educativo, especialmente, professoras e crianças, estabeleciam dependências e acordos intergeracionais quando ambas se constituíam protagonistas do processo educativo, do fazer as coisas juntas, do negociar, do trocar e do compartilhar experiências semelhantes e diversas.

Da mesma forma e de modo próprio, as crianças de idades iguais e diferentes também estabeleciam acordos e dependências intrageracionais, o que significa que as maiores também eram dependentes das menores e não somente o contrário.

Entretanto, não basta somente misturar as idades, nem apenas possibilitar a coexistência entre as gerações (Oliveira, 1999), ou entre pessoas de uma mesma geração. O que diferenciava a geração das crianças, como grupo geracional, de outras, como a das professoras, era o que se compreende como sendo a alteridade da infância, observada nas relações entre as crianças de idades iguais e diferentes, enraizada na sociedade e em sua lógica, nas políticas públicas, nas propostas educativas e, fundamentalmente, nas relações inter e intrageracionais, ou seja, entre as crianças, entre as professoras e entre crianças e professoras.

As culturas da infância são resultantes da convergência desigual de factores que se localizam, numa primeira instância, nas relações sociais globalmente consideradas e, numa segunda instância, nas relações inter e intrageracionais. Essa convergência ocorre na acção concreta de cada criança, nas condições sociais (estruturais e simbólicas) que produzem a possibilidade da sua constituição como sujeito e actor social. Este processo é criativo tanto quanto reprodutivo. 0 que aqui se dá à visibilidade, neste processo, é que as crianças são competentes e têm capacidade de formularem interpretações da sociedade, dos outros e de si próprios, da natureza, dos pensamentos e dos sentimentos, de o fazerem de modo distinto e de 0 usarem para lidar com tudo o que as rodeia (Sarmento, 2005, p. 373). 
Enfocando a construção das culturas infantis nas relações de idade entre e pelas crianças pequenas, observei que elas desconstruíam mitos e preconceitos fundados no individualismo, na competição, no autoritarismo, na imposição, na segregação e na ordem institucionalizada, especialmente, quando estavam em grupos de idades diferentes. Elas demonstravam outras ordens possíveis, como aquelas fundadas na cooperação, no cuidado, no fazer as coisas juntas.

0 estudo das relações entre estes grupos de idade implica considerar as condições sociais em que elas se dão, suas interseções com outras categorias identitárias, provocando uma reflexão no par conceitual - idade e geração - , na dinâmica política, na reprodução e na transformação social. As gerações de professoras e de crianças presentes na pesquisa não existiam isoladamente, mas possuíam referências mútuas, contraposições e, até mesmo, oposições entre elas. Ao discutir o percurso dessas gerações e o estabelecimento de relações entre elas, na instituição educativa estudada, foi possível evidenciar elementos prováveis de mudança nos modos de conceber e de se viver a infância, na construção da alteridade e do pertencimento das crianças pequenas, em relação. 


\section{Referências bibliográficas}

AGUIAR, C. M. Educação, natureza e cultura: um modo de ensinar. Tese (Doutorado) Faculdade de Educação, Universidade de São Paulo, São Paulo, 1998.

BALDUS, H. Ciclo de vida dos tapirapé. In: MOREIRA LEITE, D. O desenvolvimento da criança: leituras básicas. São Paulo: Companhia Editora Nacional; Editora da USP, v. 109, 1972. p. 49-66.

BARROS, M. L. de. Reciprocidade e fluxos culturais entre gerações. In: CONGRESSO INTERNACIONAL CO-EDUCAÇÃO DE GERAÇÕES, out. 2003, SESC/São Paulo. Disponível em: 〈http://www.sesc.org.sp.br/conferências〉. Acesso em: 06 mar. 2011.

BOSI, E. Memória e sociedade. Lembranças de velhos. 2.ed.,São Paulo: T. A. Queiroz, 1983.

BOURDIEU, P. As contradições da herança. In: LINS, D. (Org.) Cultura e subjetividade: saberes nômades. Campinas/SP: Papirus, 1997. p. 7-17.

BRITTO DA MOTTA, A. Gênero, idades e gerações. In: BRITTO DA MOTTA, A. (Org.) Caderno CRH. Dossiê: Gênero, idade, gerações - UFBA, Faculdade de Filosofia e Ciências Humanas, Centro Recursos Humanos, Salvador/BA, v.17, n. 42, p. 349-355, set./dez. 2004 .

CAIUMI, A. et al. I grandi siamo noi poi ci sono i ragazzi, poi i signori. Scuola Comunale dell'Infanzia. Diana Reggio Emilia/Italia. Anteprima, dicembre, 1999.

CALLARI GALLI, M. Antropologia senza confini: Percorsi nella contemporaneità. Palermo/Italia: Sellerio, 2005.

COHN, C. Antropologia da criança. Rio de Janeiro: Jorge Zahar, 2005.

DA MATTA, R. O ofício do etnólogo ou como ter Anthropological Blues. In: NUNES, E. de O. A aventura sociológica. Rio de Janeiro: Zahar, 1978.

DEBERT, G. G. O remapeamento do curso de vida. In: ENCONTRO ANUAL DA ANPOCS, 18., 1993, Caxambu/MG. (Mimeo).

FARIA, A. L. G. de; DEMARTINI, Z. de B. ; PRADO, P. D. (Org.) Por uma cultura da infância: metodologias de pesquisa com crianças. 3. ed., Campinas/SP: Autores Associados, 2009.

FERNANDES, F. Folclore e mudança social na cidade de São Paulo. 2. ed., Petrópolis/ RJ: Vozes, 1979.

FOOT-WHYTE, W. Treinando a observação participante. In: ZALUAR, Alba G. (Org.) Desvendando máscaras sociais. 3. ed., Rio de Janeiro: Francisco Alves, 1990. p. 77-86. 
FORTES, M. Age, generation and social structure. In: KERTZER, D. e KEITH, J. (Org.) Age and anthropological theory. New York: Cornell University, 1984. p. 137-184.

GEERTZ, C. Nova luz sobre a Antropologia. Rio de Janeiro: Jorge Zahar, 2001.

GUSMÃO, N.M. M. de. Infância e velhice: desafios da multiculturalidade. In: GUSMÃO, Neusa M. M. de. (Org.) Infância e velhice: pesquisa de idéias. Campinas/SP: Alínea, 2003. p. 15-32.

KLUCKHOHN, C. Antropologia: um espelho para o homem. Belo Horizonte/MG: Itatiaia, 1963.

LOVISOLO, H. R. Antropologia e educação na sociedade complexa. Revista Brasileira de Estudos Pedagógicos, Brasília/DF, v. 65, n. 149, p. 56-69, jan./abr. 1984.

MAKARENKO, A. S. Conferências sobre Educação Infantil. São Paulo: Moraes, 1981.

MALINOWSKI, B. A vida sexual dos selvagens. 2. ed., Rio de Janeiro: Francisco Alves, 1983.

MANNHEIM, K. O problema das gerações. In: Sociologia do conhecimento. Porto, Portugal: Res, 1928. p. 115-176.

MARTINS FILHO, A. J. ; PRADO, P. D. (Org.) Das pesquisas com crianças à complexidade da infância. Campinas/ SP: Autores Associados, 2011.

MONTES, G. O cercado da infância. Sobre os adultos, as crianças e as palavras. São Paulo: Livros do Tatu, 1991.

MORAGAS, R. Relações intergerações nas sociedades contemporâneas.In: CONGRESSO INTERNACIONAL CO-EDUCAÇÃO DE GERAÇÕES, out. 2003, SESC/São Paulo. Disponivel em: 〈http://www.sesc.org.sp.br/conferências.> Acesso em: 06 mar. 2011.

NIGITO, G. Tempos institucionais, tempos de crescimento: a gestão do cotidiano dos pequenos, dos médios e dos grandes na creche. In: BONDIOLI, A. (Org.) O tempo no cotidiano infantil: perspectivas de pesquisa e estudo de casos. São Paulo: Cortez, 2004. p. 43-95.

NOAL, M. L. As crianças Guarani/Kaiowá: o mitã reko na Aldeia Pirakuá/MS. Tese (Doutorado) - Faculdade de Educação, Universidade Estadual de Campinas, Campinas/SP, 2006.

OLIVEIRA, P.de S. Vidas compartilhadas: cultura e co-educação de gerações na vida cotidiana. São Paulo: Hucitec;FAPESP, 1999.

PAIS, J. M. Culturasjuvenis. Lisboa/Portugal: Imprensa Nacional-Casa da Moeda, 1993.

PARK, M. B. Entre vozes: crianças e velhos redimensionando práticas pedagógicas. In: REUNIÃO SOCIEDADE BRASILEIRA PARA O PROGRESSO DA CIÊNCIA, 51., 1999, Porto Alegre/RS. (Mimeo). 
PRADO, P. D. Contrariando a idade: condição infantil e relações etárias entre crianças pequenas da Educação Infantil. Tese (Doutorado em Educação) - Faculdade de Educação,Universidade Estadual de Campinas, 2006.

QVORTRUP, J. A tentação da diversidade e seus riscos. Educação e Sociedade, Campinas/SP, v. 31, n. 113, p. 1121-1136, dez. 2010.

QVORTRUP, J. Generation - an important category in sociological childhood research. Actas do Congresso Internacional Os mundos Sociais e Culturais da Infância. Braga/ Portugal: Instituto de Estudos da CriançalUniversidade do Minho, v. 2, p. 102-113, jan.2000.

RADCLIFFE-BROWN, A.R. A posição atual dos estudos antropológicos. In: ZALUAR, A. G. (Org.) Desvendando máscaras sociais. 3. ed., Rio de Janeiro: Francisco Alves, 1990. p. 176-194.

SARAMAGO, S. S. As identidades da infância: núcleos e processos de construção das identidades infantis. Sociologia - problemas e práticas, Portugal, n. 94, p. 151-171, 1994.

SARMENTO, M. J. Gerações e alteridade: interrogações a partir da sociologia da infância. Educação e Sociedade, Campinas/SP, v. 26, n.91, p. 361-378, maio/ago. 2005.

SGRITTA, G. B. (Org.) /l gioco delle generazioni. Famiglie e scambi sociali nelle Reti Primarie. Milano/Italia: FrancoAngeli, 2002.

SILVA, A.. L. da; MACEDO, A. V. da S.; NUNES, A. (Org.) Crianças indígenas: ensaios antropológicos. São Paulo: Global, 2002.

Recebido em 04 de maio de 2011 e aprovado em 30 de julho de 2012. 